\title{
Microwave-assisted silica-promoted solvent-free synthesis of triazoloquinazolinone and benzimidazoquinazolinones
}

\author{
G KRISHNAMURTHY* and K V JAGANNATH \\ Department of Studies in Chemistry, Central College Campus, Bangalore University, \\ Dr. B R Ambedkar Veedhi, Bengalore 560 001, India \\ e-mail: gkmurthy_2005@yahoo.com
}

MS received 25 April 2012; revised 18 September 2012; accepted 8 October 2012

\begin{abstract}
The derivative of triazolo/benzimidazoquinazolinones is prepared via silica-promoted solvent-free method using microwave irradiation with an excellent yield. The newly synthesized compounds were characterized by various techniques like IR, NMR and Mass spectroscopy. The compound with 1a was crystallized and analysed by single crystal X-ray diffraction studies.
\end{abstract}

Keywords. Triazoloquinazolinones; benzimidazoquinazolinones; microwave irradiation; silica gel.

\section{Introduction}

Azoles are an important structural motif in medicinal chemistry, due to their pharmacological and therapeutic activities. A number of methods have been reported and reviewed ${ }^{1}$ in this regard. Also, triazolo/benzimidazoquinazolinones are an important class of fused heterocyclic compounds found in a number of biologically active molecules. ${ }^{2}$ They have gained much more synthetic attention because of their wide range of biological/pharmacological and therapeutic activities such as antihypertensive, ${ }^{3}$ antihistaminic, ${ }^{4}$ analgesic and antiinflammatory, ${ }^{5}$ anticancer ${ }^{6}$ antitumour ${ }^{7}$ and antiHIV ${ }^{8}$ activities. Owing to their wide range of pharmacological activity, industrial and synthetic applications, a number of methods have been reported for the synthesis of triazolo/benzimidazoloquinazolinones, ${ }^{9}$ by microwave irradiation, ${ }^{10}$ conventional methods ${ }^{11}$ and more recently sulphonic acid functionalized nanoporous silica(SBA-Pr- $\mathrm{SO}_{3} \mathrm{H}$ ) catalysed by conventional solvent-free methods. ${ }^{12}$

The use of microwave irradiation for carrying out organic reactions has been well-established in recent years ${ }^{13}$ as it is an environmentally friendly method for the organic synthesis and has recently been reviewed. ${ }^{14}$ The application of the solvent-free technology coupled with the solid support has led to the development of many reaction procedures, ${ }^{15}$ using alumina ${ }^{16}$ and silica gel, ${ }^{17}$ as this technique provides an efficient method to prepare organic compounds very fast with high purity

*For correspondence and better yields. Moreover, microwave irradiation is a very clean and modern technique widely used for green chemistry synthesis.

In our laboratory, we have developed a new environmentally benign method for the synthesis of triazoloquinazolinones and benzimidazoquinazolinoes over solid support using microwave irradiation. The yields are good when compared to the reports available in the literature and also the silica-promoted reaction is an efficient greener method for the synthesis of quinazolinones. More specifically, to the best of our knowledge, this will be a novel method for the synthesis of triazoloquinazolinones and benzimidazoquinazolinoes as the reaction involved in a dry media without making use of any hazardous solvents. Also, it involves simple work-up procedure to obtain the required product with less wastage. The adsorbent silica gel was recycled and could be reused.

\section{Experimental}

\subsection{Materials and apparatus}

All solvents and reagents were commercial grade and used without further purification unless otherwise stated. The silica gel, 100-200 mesh $(0.075-0.150 \mathrm{~mm})$ was used as obtained from Spectrochem Pvt. Ltd. Mumbai. The microwave devices used were CEM Discover system (Model No. DUS107 manufactured by CEM Company in USA, with vertically focused infrared [IR] temperature control system, maximum microwave power of $300 \mathrm{~W}$, frequency at $2.455 \mathrm{GHz}$ ). 
Table 1. Silica promoted microwave-assisted solvent-free synthesis of quinazolinone derivatives $\mathbf{1 a}-\mathbf{2 h}$.

\begin{tabular}{lccccc}
\hline Entry & Amine & $\mathrm{X}$ & Product & Time $(\mathrm{min})$ & Yield $(\%)^{\mathrm{a}}$ \\
\hline 1 & 3-Amino-1,2,4-triazole & $\mathrm{H}$ & $\mathbf{1 a}$ & 4 & 90 \\
2 & 3-Amino-1,2,4-triazole & $4 \mathrm{Cl}$ & $\mathbf{1 b}$ & 5 & 95 \\
3 & 3-Amino-1,2,4-triazole & $4-\mathrm{Br}$ & $\mathbf{1 c}$ & 5 & 94 \\
4 & 3-Amino-1,2,4-triazole & $4 \mathrm{MeO}$ & $\mathbf{1 d}$ & 4 & 92 \\
5 & 3-Amino-1,2,4-triazole & $4 \mathrm{OH}$ & $\mathbf{1 e}$ & 5 & 91 \\
6 & 3-Amino-1,2,4-triazole & $4 \mathrm{Nitro}$ & $\mathbf{1 f}$ & 5 & 95 \\
7 & 3-Amino-1,2,4-triazole & $3 \mathrm{Nitro}$ & $\mathbf{1 g}$ & 5 & 96 \\
8 & 3-Amino-1,2,4-triazole & $4 \mathrm{~F}$ & $\mathbf{1 h}$ & 5 & 93 \\
9 & 2-Amino-benzimidazole & $\mathrm{H}$ & $\mathbf{2 a}$ & 3 & 95 \\
10 & 2-Amino-benzimidazole & $4 \mathrm{Cl}$ & $\mathbf{2 b}$ & 4 & 93 \\
11 & 2-Amino-benzimidazole & $4-\mathrm{Br}$ & $\mathbf{2 c}$ & 4 & 92 \\
12 & 2-Amino-benzimidazole & $4 \mathrm{Meo}$ & $\mathbf{2 d}$ & 5 & 93 \\
13 & 2-Amino-benzimidazole & $3 \mathrm{Meo}$ & $\mathbf{2 e}$ & 4 & 91 \\
14 & 2-Amino-benzimidazole & $4 \mathrm{OH}$ & $\mathbf{2 f}$ & 4 & 92 \\
15 & 2-Amino-benzimidazole & $4 \mathrm{Nitro}$ & $\mathbf{2 g}$ & 3 & 94 \\
16 & 2-Amino-benzimidazole & $4 \mathrm{~F}$ & $\mathbf{2 h}$ & 6 & 92 \\
\hline
\end{tabular}

${ }^{\mathrm{a}}=$ Isolated Yield

\subsection{Characterization techniques}

Melting points were uncorrected. Nuclear magnetic resonance spectra were obtained on a Bruker AMX spectrophotometer in DMSO at $300 \mathrm{MHz}$ instrument.
Chemical shifts were obtained in parts per million $(\delta)$ and were measured using tetramethylsilane (TMS) as reference. IR spectra were recorded on a Shimadzu FTIR-8400S Spectrophotometer using $\mathrm{KBr}$ pellets and are reported as wave numbers $\left(v \mathrm{~cm}^{-1}\right)$. Single Crystal (a)

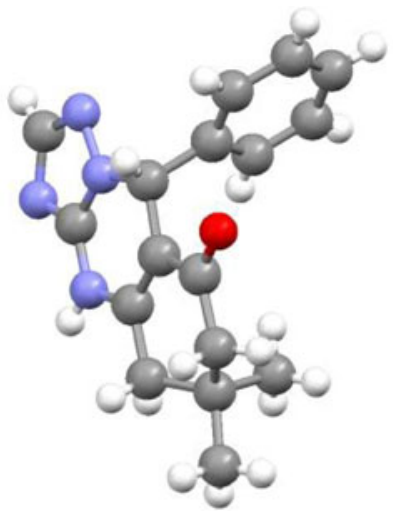

(b)
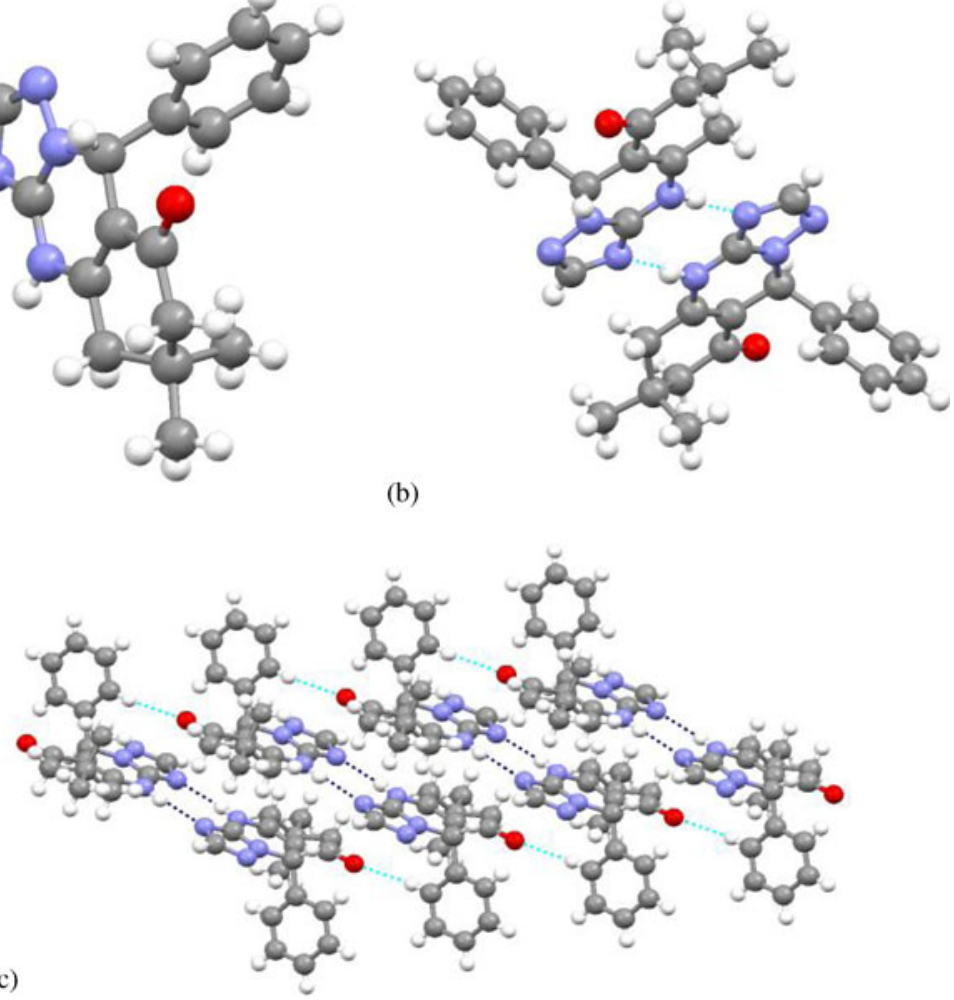

Figure 1. (a) Shows P-1 space group; (b) shows cyclic N-H...N interaction; (c) shows C-H...O hydrogen bonding interaction. 
X-ray analysis was done on Oxford Diffraction Xcalibur Eos Gemini diffractometer, ${ }^{18}$ complete crystal structure results as a CIF file including bond lengths, angles, and atomic coordinates are deposited in the Cambridge Crystallographic Data Center (CCDC 875381). ${ }^{19}$

2.2a Data collection: CrysAlis PRO (Oxford Diffraction, 2009); cell refinement: CrysAlis PRO (Oxford Diffraction, 2009); data reduction: CrysAlis PRO (Oxford Diffraction, 2009); program(s) used to solve structure: SHELXS97 (Sheldrick, 2008); program(s) used to refine structure: SHELXL97 (Sheldrick, 2008); molecular graphics: ORTEP-3 (Farrugia, 1997) and PLATON (Spek, 2009); software used to prepare material for publication: SHELXL97 (Sheldrick, 2008) and PLATON (Spek, 2009).

\subsection{General procedure for preparation of triazoloquinazo-} linone derivatives $(\mathbf{1 a}-\mathbf{1 h}) /$ benimidazoquinazolinone derivatives (2a-2h)

A Slurry of equimolar quantities of 3-amino-1,2,4triazole/2-amino benzimidazole, dimedone and benzaldehyde in a minimum quantity of ethanol/MDC was allowed to adsorb over silica gel. The solvent is removed by evaporation and the impregnated silica gel was irradiated with Microwaves of $150 \mathrm{~W}$ at $120^{\circ} \mathrm{C}$ and pressure of $100 \mathrm{psi}$ till the completion of the reaction (table 1). After completion of the reaction (as monitored by TLC), it was cooled to room temperature and the product was extracted with methylene chloride $(3 \times 15 \mathrm{ml})$. The crude product was recrystalised to get a pure compound.

$2.4 X$-ray crystal structure of 6,6-dimethyl-9-phenyl5,6,7,9-tetrahydro[1,2,4]triazolo[5,1-b]quinazolin-8(4H)one $(\mathbf{1 a})^{20}$

The compound 1a was crystallized using ethanol by slow evaporation method. In the compound 1a crystallizes in P-1 space group with one molecule in the asymmetric unit cell. The molecules are packed in the crystal by the formation of dimer by the cyclic $\mathrm{N}-\mathrm{H}$... N interaction. The molecules in a dimer are related by a crystallographic centre of inversion. Such dimers are packed in three-dimensions by the $\mathrm{C}-\mathrm{H}$... O hydrogen bonding interaction between them (figure 1). The Crystal data and other parameters are given in the table 2 . Figure 2 shows the ORTEP view of the molecule with atomic labelling and the displacement ellipsoids of non hydrogen drawn at 50\% probability level.
Table 2. Crystal data of the compound 1a.

\begin{tabular}{ll}
\hline Parameters & 1a \\
\hline Identification code & CCDC 875381 \\
Empirical formula & $\mathrm{C}_{17} \mathrm{H}_{18} \mathrm{~N}_{4} \mathrm{O}$ \\
Formula weight & 294.35 \\
Temperature & $293 \mathrm{~K}$ \\
Wavelength & 0.71073 \\
Crystal system, space group & Triclinic, $\mathrm{p}-1$ \\
Unit cell dimensions & $\mathrm{a}=6.0555(14) \AA ;$ \\
& $\alpha=74.08(2)$ \\
& $\mathrm{b}=10.986(3) \AA ;$ \\
& $\beta=75.86(2)$ \\
& $\mathrm{c}=12.285(3) \AA ;$ \\
Volume & $\gamma=76.96(2)$ \\
Z, Density & $751.0(3) \AA$ \\
Absorption coefficient & $2,1.302 \mathrm{~g} / \mathrm{cm}^{3}$ \\
F(000) & $0.085 \mathrm{~mm}^{-1}$ \\
Crystal size & 312 \\
Theta max & $0.03 \mathrm{~mm} \times 0.02 \mathrm{~mm} \times$ \\
h k 1 max & $0.02 \mathrm{~mm}$ \\
N ref & 28.870 \\
R indices (all data) & $8,14,16$ \\
N par & 3952 \\
& $\mathrm{R} 1=0.0886(1628)$ \\
& 200 \\
&
\end{tabular}

\section{Results and discussion}

In search of an effective green method for the synthesis of stated compounds, initially we took different solid supports like montmorillonite K10, acidic alumina and silica gel. Among these, silica gel and acidic alumina have given better result in obtaining the product 1a. We

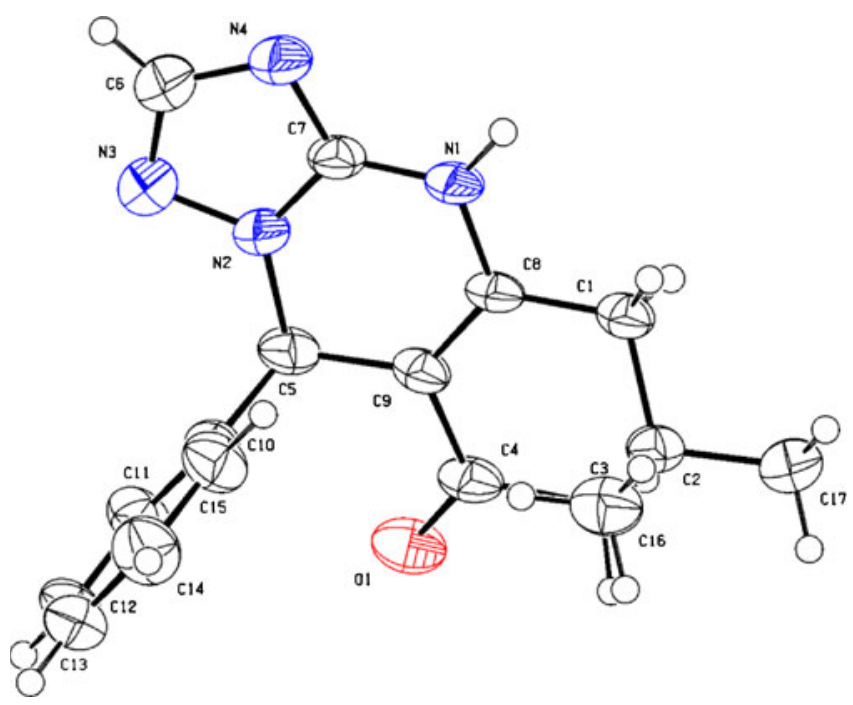

Figure 2. The ORTEP diagram of the compound 1a showing the displacement ellipsoids of non-hydrogen atoms drawn at the $50 \%$ probability level. 
Table 3. Synthesis of 9-(phenyl)-6, 6-dimethyl-5, 6, 7, 9-tetrahydro-1, 2, 4-triazolo [5, 1] quinazolin-8-one. (1a) and 12(phenyl)-3,3-dimethyl-1,2,3,4,5,12-hexrahydrobenzo[4, 5]imidazo[2,1-b]- quinazolin-1-one (2a) at different temperature.

\begin{tabular}{lrlll}
\hline & & & \multicolumn{2}{c}{ Yield $(\%)^{\mathrm{a}}$} \\
\cline { 4 - 5 } Entry & Temperature ${ }^{\circ} \mathrm{C}$ & Time & $\mathbf{1 a}$ & $\mathbf{2 a}$ \\
\hline 1 & 80 & 5 min & 80 & 80 \\
2 & 100 & 4 min & 85 & 85 \\
3 & 120 & 4 min & 85 & 90 \\
4 & 120 & 4 min & 92 & 95 \\
\hline
\end{tabular}

$\mathrm{a}=$ Isolated Yield

have chosen silica gel as a solid support in all subsequent experiments. Initially, the synthesis was carried out using household microwave oven (ONIDA POWER SOLO 20). These reactions have yielded the products up to $75 \%$ and above. However, the time taken in these reactions was nearly 15-20 min much faster when compared to the conventional methods. When these reactions were carried out using CEM microwave synthesizer, the products are obtained within 3-4 min with $>90 \%$ yield. From table 3 it is clear that the optimized condition for the reaction, by varying the temperature from $80^{\circ} \mathrm{C}$ to $120^{\circ} \mathrm{C}$ and pressure of $100 \mathrm{psi}$, a good yield was obtained with in 4 min of irradiation at $120^{\circ} \mathrm{C}$.

A series of reactions were carried out using a CEM discover microwave. These reactions have yielded the products of about $90-95 \%$ within a short time of $3-$ 5 min (table 1, scheme 1) of irradiation. These experimental results indicate the faster reactions with good yields when compared to the reported methods, and moreover it is an environmentally benign green method. All the compounds are known, except $\mathbf{1 h}$ and $\mathbf{2 h}$. The products were characterized by melting points, IR, NMR \& Mass spectra and compared with those reported for the authentic samples. The compound 1a was only crystallized and characterized by single crystal X-ray analysis.

\subsection{Spectral data for new compounds}

3.1a 9-(4-Fluro-phenyl)-6, 6-dimethyl-5, 6, 7, 9tetrahydro-4H-1, 2, 4-triazolo [5, 1-b] quinazolin-8one (1h): Yield: 93\%, mp 258-260 ${ }^{\circ} \mathrm{C} .{ }^{1} \mathrm{H}$ NMR (DMSO, $300 \mathrm{MHz}): \delta$, ppm, 0.85 (s, 3H), 1.01 (s, 3H), $2.05(\mathrm{~d}, \mathrm{~J}=16.11 \mathrm{~Hz}, 1 \mathrm{H}), 2.25(\mathrm{~d}, \mathrm{~J}=16.17 \mathrm{~Hz}, 1 \mathrm{H})$, 2.48-2.52 (m, 2H), $6.21(\mathrm{~s}, 1 \mathrm{H}), 7.09(\mathrm{~d}, \mathrm{~J}=8.82 \mathrm{~Hz}$, $2 \mathrm{H}), 7.21(\mathrm{~d}, \mathrm{~J}=7.09 \mathrm{~Hz}, 2 \mathrm{H}), 7.68(\mathrm{~s}, 1 \mathrm{H}), 11.14$ (s, 1H). IR (K Br): $v_{\max }=2669-3454,1650,1550$, $1471,1338 \mathrm{~cm}^{-1}$ HRMS $\mathrm{m} / z$ : calculated 312.1 found $335.1284[\mathrm{M}+\mathrm{Na}]$.

3.1b 12(4-Fluro-phenyl)-3,3-dimethyl-1,2,3,4,5,12hexrahydrobenzo[4,5]imidazo[2,1-b]-quinazolin-1-one $(2 \boldsymbol{h})$ : Yield: $92 \%, \mathrm{mp}>300^{\circ} \mathrm{C} .{ }^{1} \mathrm{H}$ NMR (DMSO, $300 \mathrm{MHz}): \delta$, ppm, 0.95 (s, 3H), 1.05 (s, 3H), 2.04 (d, $\mathrm{J}=16.11 \mathrm{~Hz}, 1 \mathrm{H}), 2.20(\mathrm{~d}, \mathrm{~J}=16.00 \mathrm{~Hz}, 1 \mathrm{H}), 2.58$ $2.62(\mathrm{~m}, 2 \mathrm{H}), 6.48(\mathrm{~s}, 1 \mathrm{H}), 7.00-7.89(\mathrm{~m}, 8 \mathrm{H}), 11.00$ (s, 1H). IR (K Br): $v_{\max }=3440,2955,1644,1613$, 1589, $1565 \mathrm{~cm}^{-1}$ HRMS $\mathrm{m} / z$ : calculated 362.1669 found $362.1665[\mathrm{M}+\mathrm{H}]$.
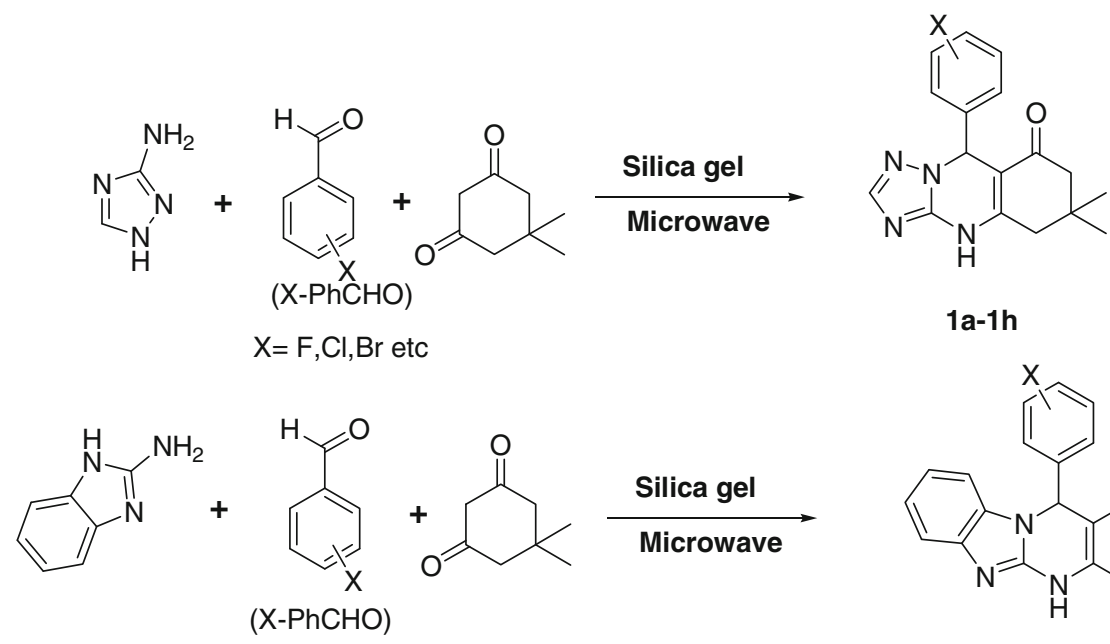

$\mathrm{X}=\mathrm{F}, \mathrm{Cl}, \mathrm{Br}$ etc

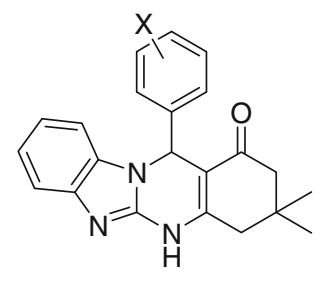

2a-2h

Scheme 1. Synthesis of triazoloquinazolinone derivatives (1a-1h)/benimidazoquinazolinone derivatives (2a-2h). 


\section{Conclusion}

In summary, we have successfully developed silicapromoted in tandem with condensation-cyclization leading to the formation of triazolo- or benzimidazoquinazolione heterocycles. The method is simple, under solvent-free conditions and environmentally benign. The single crystal X-ray studies were made for the compound 1a.

\section{Supplementary information}

CCDC 875381 contains the supplementary crystallographic data for this paper. These data can be obtained free of charge from The Cambridge Crystallographic Data Centre via www.ccdc.cam.ac.uk/data_request/cif.

\section{Acknowledgements}

The authors thank the University Grants Commission (UGC-DRS), (UGC-DSA) and the Department of Science and Technology (DST)-FIST for the Instrumental facility at our Department Premises, Bangalore University Internal Research Fund (BUIRF) Bangalore University for financial support, and Indian Institute of Science (IISc), Bangalore for Spectral studies. KVJ thanks SC/ST cell of Bangalore University for research fellowship.

\section{References}

1. David J C, Declan C, Timothy P S and Patrick J G 2005 Tetrahedron 6110153

2. Liu K C and Hu M K 1986 Arch. Pharm. 319188

3. Alagarsamy V and Pathak U S 2007 Bioorg. Med. Chem. 513457

4. Alagarsamy V 2004 Pharmazie 59753

5. Alagarsamy V, Murugananthan $\mathrm{G}$ and Venkateshperumal R 2003 Biol. Pharm. Bull. 261711

6. Hour M J, Huang L J, Kuo S C, Xia Y, Bastow K, Nakanishi Y, Hamel E and Lee K H 2000 J. Med. Chem. 434479
7. Xia Y, Yang Z Y, Hour M J, Kuo S C, Xia P, Bastow K F, Nakanishi Y, Nampoothiri P, Hackl T, Hamel E and Lee K H 2001 Bioorg. Med. Chem. Lett. 111193

8. Alagarsamy V, Revathi R, Meena S, Ramaseshu K V, Rajasekaran S and De C E 2004 Indian J. Pharm. Sci. 66459

9. Lipson V V, Desenko S M, Shirobokova M G and Borodina V V 2003 Chem. Het. Comp. 391213

10. Aboul-Fetouh E M, Ashraf A A, Hassan H F and Eman A B 2007 Beilstein J. Org. Chem. 3 11, doi:10.1186/ 1860-5397-3-11

11. (a) Heravi M M, Ranjbar L, Derikvand F, Alimadadi B and Oskooie H A 2008 Mol. Divers. 12 181; (b) Heravi M M, Ranjbar L, Derikvand F and Ranjbar L 2010 Synth. Commun. 40677

12. Zirani G M, Alireza B, Zeinab A and Negar L 2011 Arabian J. Chem., doi:10.1016/j.arabjc.2011.06.020

13. (a) Oliver K 2004 Angew. Chem. Int. Ed. 43 6250; (b) Oliver K 2005 Microwaves in organic and medicinal chemistry, Alexander Stadler, Weinheim: Wiley-vch Verlag GmbH \& Co. KGaA

14. Oliver K and Doris D 2006 Nature Reviews Drug Discovery 551

15. Tanaka K and Toda F 2000 Chem. Rev. 1001025

16. (a) Alexander Y U and Yuri L K 2000 Tetrahedron Letters 41 5031; (b) Kidwai M, Misra P, Bhushan K R, Saxena R K and Singh M 2000 Monatsh. Chem. 131937

17. Veena Y and Nishant Y 2011 Archives Applied Science Reseasrch 3(1) 139

18. (a) Oxford Diffraction 2009, Crys alis PRO. Oxford Diffraction Ltd, Yarnton, England; (b) Sheldrick G M 2008 Acta. Cryst. A64 112; (c) Farrugia L J 1997 J. Appl. Crystallogr. 30 565; (d) Sheldrick G M 1997 SHELXS97 and SHELXL-97, Program of Crystal Structure Refinement (University of Göttingen, Germany)

19. Details of X-ray single crystal structure determination of 1a was deposited at CCDC (deposition No. CCDC 875381)

20. 6,6-dimethyl-9-phenyl-5,6,7,9-tetrahydro[1,2,4]triazolo [5,1-b]quinazolin-8(4H)-one(1a). Light yellow solid $(90 \%), \mathrm{mp}=248-250{ }^{\circ} \mathrm{C} .{ }^{1} \mathrm{H}-\mathrm{NMR}$ (DMSO-d6, $300 \mathrm{MHz}$ ): $\delta$, ppm, 0.95 (s, 3H),1.03 (s, 3H), 2.07 (d, $\mathrm{J}=16 \mathrm{~Hz}, 1 \mathrm{H}), 2.21(\mathrm{~d}, \mathrm{~J}=16 \mathrm{~Hz}, 1 \mathrm{H}), 2.49(\mathrm{~m}, 2 \mathrm{H})$, $5.90(\mathrm{br}, 1 \mathrm{H}), 7.16-7.27(\mathrm{~m}, 5 \mathrm{H}), 7.67(\mathrm{~s}, 1 \mathrm{H}), 11.02(\mathrm{~s}$, 1H). IR (KBr): v: 1650, 1587, 1546, 1473, $1415 \mathrm{~cm}^{-1}$; LC-MS m/z: C17H18N4O calculated 294.35 found $295.2[\mathrm{M}+\mathrm{H}]$ 